\title{
Business Management and Innovation: A Critical Analysis of Small Business Success
}

\author{
Francis Mbah Takwi \\ Faculty of Business Management and Sustainability, Information and Communication Technology University USA, Yaounde, Cameroon
}

Email address:

francis.takwi@ictuniversity.org

\section{To cite this article:}

Francis Mbah Takwi. Business Management and Innovation: A Critical Analysis of Small Business Success. American Journal of Operations Management and Information Systems. Vol. 5, No. 3, 2020, pp. 62-73. doi: 10.11648/j.ajomis.20200503.15

Received: September 7, 2020; Accepted: September 23, 2020; Published: October 12, 2020

\begin{abstract}
In a management field, success and failure can be interpreted as measures of good or indifferent management, but it may occur for other reasons such as luck. Numerous terms have been used in the literature to describe firm failure, for example: bankruptcy, insolvency, liquidation, death, deregistering, discontinuance, ceasing to trade, closure, and exit. The overall aim of this research was to develop a clearer understanding of the factors that influence success of Micro Enterprises in Bamenda, as perceived by local Small business managers. The prime motive for conducting this study is to get a comprehensive model relating to the various success factors for small business managers. The mixed methods approach is used to avoid common method bias that could affect the results of this research study. In the first phase, a quantitative approach was employed in the form of a survey questionnaire, in order to identify the critical success factors for Small businesses in the city of Bamenda as perceived by Small business managers and to classify and compare successful and less successful Small businesses with respect to the identified factors. The second phase adopted a qualitative approach to explore how Small business Small business managers see the factors that facilitate business 'success' in relation to their experiences in Bamenda. This study has shown that understanding the success of small businesses from the perspective of small business managers is a complex challenge. Findings of the two phases of the study showed that a host of internal as well as external factors, which are usually moderated by other variables, seem to influence business success in Bamenda. However, while many factors are conceptually similar to other studies in different contexts, others are context-based and closely linked to the specific characteristics of the situation in Bamenda. This finding suggests a close relationship with networking and business success. It can be suggested that the ability to develop relationships and to build a method of business that strengthens and manages relationships is a significant factor in Cameroonian business and society in general.
\end{abstract}

Keywords: Small Business Growth, Business Innovation, Entrepreneurship, Business Success

\section{Introduction}

\subsection{Study Background}

The important contribution of a vibrant Small businesses sector in the national economic and social development of a country has been widely recognized. In view of its increasing importance, the success of small businesses has been of interest to researchers, international organizations, and policy makers, at least since the Bolton report (1971), [6] and therefore has become the subject of a great deal of analysis. Attention to the Small business sector has heightened because of the globalizing economy and the increasingly severe competition that is inherent in this development.
The importance of Small businesses is well recognized in academic and policy literature [18]. Both developed and developing countries have realized the importance of Small businesses in economic and social development. In Europe, the annual report of European Small businesses confirmed that Small businesses remain the European Union's economic backbone despite the global financial crisis [1]. Representing 99.8 per cent of all enterprises, Small businesses contribute to 66 per cent of employment in the European Union. Small businesses in Cameroon play a pivotal role in the development of the country. The importance of Small businesses is evidenced by their high presence in the economic structure of the country. According to The United Nations Economic Commission for Africa (UNECA) in 
2008, stated that $90 \%$ of all Cameroonian firms are Small businesses and account for $40 \%$ of production, $42 \%$ of investment, $35 \%$ of exports and $50 \%$ of all jobs.

Through the conclusion of a series of free trade agreements with its main trading partners (European Union), Cameroon has embarked in a global economy characterized by fierce competition. This has left no choice for Small businesses but to adapt to the hostile environment and engage in the process of identifying strategies to ensure their business success. Given this situation and being aware of the socio-economic importance of Small businesses, the Cameroonian government has been taking necessary measures and actions to promote the sector and ensure its success. In this regard, the government has deployed the Emergence Covenant that aims to develop a very competitive Small business sector [12].

\subsection{Statement of the Problem}

Although Bamenda has a very strategic location compared to other cities in Cameroon, the report revealed that Bamenda was the most difficult area in the ease of doing business. This left the author with a profound feeling of anxiety about the success factors of small business managers and owner managers in Bamenda. What made Small businesses to grow and flourish in this hostile environment was the main motivation behind this study.

The performance of Small Businesses has been of interest to many researchers, international organizations, and policy makers, at least, since the Bolton report (1971), [6] and therefore has become the subject of a great deal of analysis. This performance may have two strategic outcomes that are often referred to in the literature as firm success or failure. In a management field, success and failure can be interpreted as measures of good or indifferent management, but it may occur for other reasons such as luck [18].

Numerous terms have been used in the literature to describe firm failure, for example: bankruptcy, insolvency, liquidation, death, deregistering, discontinuance, ceasing to trade, closure, and exit. These terms overlap each other to some extent and thus, the concept of failure is ambiguous, as it can have different interpretations by different people [11]. The many different interpretations and definitions of both success and failure make it very hard to compare research findings on the performance of small firms.

Very often, the terms 'success', 'survival', 'growth' are very closely linked and sometimes used interchangeably. Besides the multi-dimensional aspect of success, variables that contribute to the success of Small business managers are not unanimously agreed upon by researchers. While some analysts suggested that the dynamics of the success of businesses remain a black box, others argued that the success of enterprises is a function of both external and internal factors [1].

Literature on the performance of Small Businesses usually identifies several causal factors with regard to the internal and external environment of the firm. In terms of internal factors, several researchers have attempted to investigate the antecedent factors that personally influence the small business manager and the external and internal factors that influence Small Businesses performance [18]. For the firm characteristics, several studies have revealed that size, age, and location of the firm could be related to business performance. On the other hand, other researchers have shown great interest in understanding the relationship between traits of the small business manager and business performance [4].

For the general environment, data from several sources have identified economic factors, in particular financial resources and taxation, as central for the success of businesses [22]. Other studies have found that political legal factors significantly relate to business performance [19]. Much literature has focused on the technological factors. These studies have highlighted the positive relationship between technology, information, and infrastructure and business performance. The networking factor, which could be classified under the socio-cultural factors, has been subject to a great deal of research. Numerous studies have documented a positive association between networking and various aspects of firm performance.

On the other hand, a large and growing body of literature has investigated the competitive environment of the firm in relation to three stakeholders: customers, suppliers, and competitors. There is a large volume of published studies describing the role of customer relationship management as a key factor in business performance. Similarly, an increasing amount of literature has highlighted the effect of suppliers on the performance of businesses. Other researchers have argued that an analysis of the role of competitors and countercompetition intelligence and actions are crucial for the survival of a Microenterprise [11].

Small business managers are driven to achieve success by several motivators. A driving force for most owner managers to succeed in business was poverty. There is also a strong desire to provide a better life for their children, which is the result of the small business manager's own economically deprived childhood. They have a determination to succeed and have control of their life. They achieve self-determination by economic independence. The need to network and interact with non-indigenes of Bamenda is therefore essential for thefr business success. The intrinsic motivator for small business managers is to provide for their family, to give their children a better life than what they experienced, and to escape the entrapments of poverty. Discrimination combined with lack of capital and access to micro-credit was seen as the major inhibitors to business success. These broad ranging topics were seen to be of related interest and in the spirit of the smdy, deemed to require further discussion.

As argued by Man and Lau Small businesses are more likely than larger firms to be affected by changes in their internal and external environment. Thus, an important issue arises concerning the ability of small and medium firms to cope in a very challenging environment [9]. In attempt to address this issue, the present study has been undertaken with the aim of developing a clearer understanding of the factors 
that influence success of Small businesses in Bamenda, as perceived by local Small business managers.

\subsection{Research Objectives \& Questions}

\subsubsection{Research Objectives}

The overall aim of this research is to develop a clearer understanding of the factors that influence success of Small Businesses in Bamenda, as perceived by local Small business managers. In order to achieve this overall research aim, three key objectives are set:

1. To identify the salient factors for business 'success' in the opinion of Small business Small business managers in the city of Bamenda;

2. To examine differences between owner-managers of 'successful' and 'less successful' Small businesses in relation to the identified salient factors; and

3. To explore the experiences of start-up managers of the perceived factors contributing to business success.

\subsubsection{Research Questions}

The aim of this research is to answer the following questions about the business and personal success of Small business managers in Bamenda in respect to the theoretical framework identified from the literature review:

1. What are the salient factors for business 'success' in the opinion of Small business $\mathrm{s}$ managers in the city of Bamenda?

2. With reference to the identified salient success factors, what differences, if any, exist between the 'successful' and 'less successful' Small businesses?

3. How do Small businesses Small business managers in Bamenda see these factors for business 'success' in relation to their social environment in the city of Bamenda?

\subsection{The Rationale of the Study}

The prime motive for conducting this study is to get a comprehensive model relating to the various success factors for small business managers. Although there have been a number of studies, these have focused solely on a narrow range of financial success measures. None of these prior studies adopted a systematic review process and the majority of them lie in the grey literature. Arguably, this limits their value and explains their limited research approaches. The need for this present study seems therefore self-evident. Based on a systematic literature review, the study addresses this knowledge gap by developing a comprehensive model of various success factors in the context of Bamenda, using both financial and non-financial measures of performance. It is the first study to be conducted in such context.

Bamenda is unequivocally a cosmopolitan city, rich in historical and multi-cultural background. The choice of Bamenda in rests firstly on its strategic location, secondly on the recent and increasing investment in the city and thirdly its role as the third most important business city in Cameroon.

The present study is expected to make a number of contributions in a number of ways. From a theoretical perspective, the study adds new knowledge and extends the growing body of literature in the field of Entrepreneurial Business Innovation. The study has the potential to contribute to the understanding of the critical success factors for Small business managers in the city of Bamenda. It is designed to give rise to a situational model, based on the Bamenda small business managers' perceptions, that enriches current research by offering new insights with rich information on the factors that tend to be perceived as associated with business success, which has not been done before in this geographical context. From a practical perspective, understanding business success through the different perceived factors covered in this present study is very important. This study could provide Small business managers of Small businesses with knowledge and guidance about the way they could manage and run their businesses in a very successful manner.

\section{Research Methodology}

\subsection{Research Questions and Objectives Revisited}

This research study sought to explore issues surrounding the successful performance of Small businesses in Bamenda from the perspective of local Small business managers, informed by the theoretical framework identified from the literature review. The questions that guided and focused the study were as follows:

1. What are the salient factors for business 'success' in the opinion of Small business Small business managers in the city of Bamenda?

2. With reference to the identified salient success factors, what differences, if any, exist between the 'successful' and 'less successful' Small businesses?

3. How do Small business Small business managers in Bamenda see these factors for business 'success' in relation to their social environment in the city of Bamenda?

The overall aim of this research was to develop a clearer understanding of the factors that influence success of Micro Enterprises in Bamenda, as perceived by local Small business managers. To achieve the research aim, three key objectives were set out:

1. To identify the salient factors for business 'success' in the opinion of Small business Small business managers in the city of Bamenda;

2. To examine differences between owner-managers of 'successful' and 'less successful' Small businesses in relation to the identified salient factors; and

3. To explore the experiences of start-up managers of the perceived factors contributing to business success.

\subsection{The Research Approach}

The post-positivist philosophy adopted in this research study stresses the use of multiple methods, which might include quantitative and qualitative techniques. Moreover, in descriptive research, the techniques most often used to 
collect, analyse and summarize data are quantitative techniques, whereas an exploratory study often uses qualitative techniques. Therefore, a mixed methods approach, incorporating both quantitative and qualitative data, is deemed to be appropriate to carry out this study in order to improve the quality of the research. It should be clarified here that the research used a sequential mixed-methods strategy whose logic became emergent during the course of the research - in other words, he mixed-methods approach developed as the research went along. The study initially followed the tradition used in Business management research, which has historically been primarily positivist in its paradigmatic stance, using purely quantitative approaches. Although there has been some movement away from purely quantitative approaches, attention to qualitative methods has generally been limited. Although results found from the adoption of the quantitative approach were important, they were however inconclusive since constructs used in the survey, derived from the literature, were imposed on respondents. This did not allow an enough understanding of participants' personal view of the salient factors that influence business success. Due to the inconclusive nature of the quantitative survey, it was decided to conduct further research using a qualitative strategy. The quantitative research, however, was vital in order to provide a spring board for the qualitative phase. It aimed to profile respondents according to financial and non financial criteria (e.g. turnover, personal satisfaction) and provided the selection of interviewees that would be able to respond to the issues that were explored further. The reason for the second phase is then derived from the need to illuminate the quantitative findings and potentially enhance our understanding of the salient factors of success in Bamenda. Thus, the combination of a mixed methods approach is used in order to provide richer in-depth understanding and insights into participants' perspectives of small business managerial success. Furthermore, the mixed methods approach is used to avoid common method bias that could affect the results of this research study. Having critically reviewed the literature systematically and built the theoretical framework, a quantitative approach, using deductive reasoning, was utilised in order to gather appropriate data, test the theoretical framework and gain general understanding of the factors that influence the success of Small business managers in Bamenda. Following that, a qualitative approach, using inductive reasoning was adopted. The qualitative approach was carried out at this second stage in order to gain an indepth understanding over the generalized data and to enable the building of the final situational model related to the success of Small business managers in Bamenda.

\subsection{Sampling Procedure}

To carry out a census, the population of interest has to be clearly and accurately defined. Babbie defined a population as all elements (individuals, objects and events) that meet the sample criteria for inclusion in a study [3]. According to Polit and Hungle a population is the totality of all subjects that conform to a set of specifications, comprising the entire group of persons that is of interest to the researcher and to whom the research results can be generalized. In order to define the population of this study, several steps were required to come up with the list of Small business managers to be studied [15]. The first step was to decide on the Small businesses definition that will be used to define the population. There is no universally agreed definition of Small businesses. The definition varies from country to country depending on the size of the economy. In Cameroon, several definitions exist.

However, the official definition was used based on the number of employees. The latter was chosen in accordance with the argument of Child who argued that employment is an adequate criterion for the measurement of the size of an organisation, because it is above all human beings who are 'organized' [7]. Therefore, this research study considered enterprises with a headcount between 1 and 10 employees as Small businesses. Having decided on the definition to be used for Small businesses to define the population in Bamenda, the second step consisted of the selection of an official and reliable source of information to identify the Small businesses. All Small businesses operating in Bamenda Cameroon were identified. In order to include up-to-date information about Small businesses, other up-to-date sources of information were needed. Small businesses were cross-checked. The cross checking task resulted in deleting four enterprises from the identified initial list since they had more than 100 employees. Having completed all these steps, a final list of up to date Small businesses, comprising 200 enterprises, was created.

In the light of this, it should be noted here that the population identified by researcher was less than 500 Small businesses in Bamenda.

\subsection{Data Collection}

Following the refinement of the questionnaire, data collection was carried out. The questionnaire was distributed to the business Small business managers of the selected firms. The distribution of the questionnaire was done in two phases: The 'drop and collect' phase and the online phase.

\subsubsection{Drop and Collect Phase}

This phase took place in November 2016. Companies were approached in person. The purpose of the study was explained to them, and they were briefed about the ethical considerations and then were asked to fill in the questionnaire. It should be noted here that network connections were used in order to ease the access to these enterprises. Some Small business managers did fill in the questionnaire on the spot, whereas, some others requested their collection at a later time. A time frame of one week was agreed in order to allow these Small business managers to fill in the questionnaire at their convenience. The process was completed in three weeks, precipitating a total of 97 collected questionnaires.

\subsubsection{The Online Phase}

The questionnaire was also administered online. This phase took place in December 2016 and January 2015. 
Emails were sent to the distribution list, created in a mail box 'feedback Cameroon', which contained the list of Small businesses with email addresses identified.

A number of steps were incorporated in this phase. In the first step, an email giving an overview about the study and its purpose was sent on the 10th December 2016 to 100 enterprises. The email invited the Small business managers of the enterprises to fill in the online English questionnaire following the link that was clearly included in the email. The online questionnaire was designed in such a way that respondents could stop in the middle of the survey, if they wished, by using the 'postpone' and 'resume later' buttons. This function was to allow respondents to complete the questionnaire at their own convenience. The deadline was set for 15th December 2016. Only two enterprise filled in the English questionnaire and did provide its name and address in order to get the results of the study.

Having received only five responses, a move to the second step was then required. A first reminder was sent to the enterprises, excluding the enterprise that replied to the first email and the enterprises whose emails bounced. The reminder addressed again the purpose of the study and explained that a French version of the questionnaire has also been developed besides the English version. The Small business managers of Small businesses were then invited to fill in the questionnaire in the language they feel most comfortable with. The deadline was set for 20th December 2016.

Following the low number of responses, a decision to move to the third step was taken by sending a second courtesy reminder. The reminder explained that few responses had been received but that, to get more accurate and robust results, the research still needed more participants to share their views about the study. Therefore, the reminder provided an extension of deadline to the participants. The deadline was set for 24th December 2016. This step triggered only two responses. The low number of responses could be explained by the fact that December is a month in which enterprises undertake their inventory audits and thus they were busy and did not have time to fill in the questionnaires.

In total, 104 questionnaires were returned: 97 in the initial 'drop and collect' phase and 7 after prompting. This was an overall response rate of $30 \%$. Of the 104 questionnaires received, 4 were discarded as incomplete, meaning that 100 fully completed questionnaires were returned, providing a net response rate of $35 \%$.

It should be made clear that this study is not unusual in terms of difficulty experienced in obtaining responses from Small business Small business managers, as other researchers have reported similar problems. [8] suggest that a major difficulty in any research that involves surveying small businesses is achieving an adequate response rate, with many studies reporting rates as low as $10 \%$.

\subsubsection{Interview Administration}

The data collection for the qualitative phase took place from October 2016 to December 2016. It was carried out in two separate time frames due to logistical and practicable reasons. Arrangements were made to meet up with Small business managers in November 2007 to carry out more interviews. As a result, another ten interviews were conducted within this month totalling to a number of fifteen interviews. The break between the two interview periods did provide time to reflect on the preliminary analysis of the interviews. All interviews were individual, face-to face interviews and were conducted using the Enlish language. The duration of the interviews ranged from 30 to 60 minutes. With regard to the settings, the strategy was to allow all informants to choose the location so as they could feel more relaxed. The strategy resulted in nine interviews being conducted at the participants' business premises, five in a coffee shop, and one while driving a car.

Prior to undertaking each interview, a verbal brief about the aim of the study and issues related to confidentially was given to participants. The permission to audio record the interview by a digital recorder was sought from the interviewee. Permission was granted and all the fifteen interviews were audio recorded. Furthermore, ownership and copyright of transcripts were established at this stage and participants were informed that transcripts will be destroyed once the research study has come to an end.

During the interview, an open-ended flexible approach to interviewing, was used. Thus, open-ended questions were deliberately asked to encourage participants to engage in the conversation. The flexible approach was useful and did result in new emerging issues to be explored. Furthermore, participants' responses were frequently rephrased and repeated in order to ensure accurate understanding of the main points and encourage the interviewees to expound their views on these points.

At the end of the interview, a standard form was given to participants to fill in their personal characteristics such as: age, gender, and educational background, as well as the firm characteristics such as: legal status, activity of the enterprise, years in business, and number of employees. Moreover, participants were reassured again about the confidentiality issues and were alerted that they could be contacted should the researcher need more clarification.

Before conducting the interview, time and location should be agreed with the participants. The interview schedule and location was established at the convenience of the participants. At the start of each interview, participants were reassured that all information will be kept confidential and that their anonymity will be respected. Furthermore, participants were asked whether they have any objection to the use of audio recorder during the interview. The interviewer then explained the nature and aim of the research. During the interview process, notes were taken in addition to the audio recording, in case of any technical failure with the equipment used. At the end of the interview, the participant was thanked for taking part and reassured again that confidentiality and anonymity will be respected.

\subsection{Data Analysis}

Quantitative data refers to numerical and standardized 
data, which usually can be analysed through using of diagrams and statistics. In this research study, the process of analysing quantitative data included: data preparation, descriptive analysis, inferential analysis, and content analysis. In order to analyse the data, the software Microsoft Excel with add-ons was used. The reason for this is that the software allows the discovery of differences and relationships in data. As mentioned previously in section the developmental phase, the levels of measurement were not considered in this study.

\section{Discussion of Findings}

At the outset, it was stated that the overall aim of this research study was to develop a clearer understanding of the factors that influence success of Micro Enterprises in Bamenda, as perceived by local Small business managers. To achieve this aim, the study utilized a "mixed-method" approach. In the first phase, a quantitative approach was employed in the form of a survey questionnaire, in order to identify the critical success factors for Small businesses in the city of Bamenda as perceived by Small business managers and to classify and compare successful and less successful Small businesses with respect to the identified factors. The second phase adopted a qualitative approach to explore how Small business Small business managers see the factors that facilitate business 'success' in relation to their experiences in Bamenda.

The present section discusses the findings of both the quantitative and qualitative phases. Discussion of the findings is made in accordance to the objectives of the study, with reference to the theoretical overview outlined in the systematic literature review.

\subsection{Individual Success Factors}

\subsubsection{Socio-demographic Characteristics}

\section{i. Age of the Small Business Manager}

Findings of the quantitative phase revealed a significant association between the age of the small business manager and business success. Descriptive statistics indicated that the majority of successful small business managers were between the ages of 25 and 45 . Moreover, results of the inferential analysis, showed significant differences between successful and less successful Small businesses in Bamenda, in relation to the age of the small business manager. Findings suggested that the small business managers in the younger age category were more likely to be Small business managers of successful businesses. Not surprisingly, the findings reflect the age structure of the Cameroonian population that is characterised by the predominance of youth.

The finding of the present study would appear to be at odds with the research of [26] who found that among the failure factors of Small businesses in Cameroon is the relatively young age of the small business managers $(<35$ years). It also contradicts the findings of [26] who undertook an exploratory study of Small business manager and firm characteristics to identify the factors affecting the growth of Small businesses in Nigeria. Specifically, using a survey selfadministered questionnaire on a sample of 523 Small business Small business managers, their study reported that middle-age and older Small business managers tend to run more growth oriented firms. However, it is consistent with those undertaken in different contexts, such as the study of [17] who found that individuals aged 25-44 years were the most small business managerially active. A possible explanation of the findings from this study is that while some of the younger Small business managers in Bamenda do indeed make serious mistakes and fail, those that survive tend to manage with a stronger growth orientation.

\section{ii. Gender}

In the quantitative phase of the study, the gender variable was found to have no significant association with business success. Descriptive statistics indicated that the majority of Agribusiness firms were owned or managed by men. In fact, only ten of the respondents were female; and this did not allow for statistical analysis. This could be explained by different factors related to the social structure of Cameroon. In addition, results of the inferential analysis, showed no significant differences between successful and less successful Small businesses in Bamenda, in relation to the gender of the small business manager. An explanation is that given a sample within which the vast majority of respondents are of the same gender, a valid comparison between genders is impossible.

\subsubsection{Background Characteristics}

\section{i. Education}

The quantitative data analysis revealed that education of the small business manager seems to have a paramount importance in ensuring the success of Small business managers in Bamenda. Descriptive statistics revealed that the proportion of Small business managers who have attained high levels of education is higher in successful firms compared to their counterparts in less successful firms. Additionally, results of the inferential analysis, using the Mann-Whitney $U$ test, revealed significant differences between successful and less successful Small businesses in Bamenda, in relation to the education of the small business manager. Findings of both descriptive and inferential statistics suggested that Small business managers of successful firms are characterised with relatively higher levels of education than their counterparts in less successful Small businesses in Bamenda. This suggests that there is a strong link between the education of the small business manager and success of the firms. The finding shows similarities to previous studies conducted in Cameroon. Specifically, the finding supports the study of [5] who found that education of the small business managers was helpful for the success of their firms. Furthermore, it seems to be consistent with the study of [26], who showed that the poor education of small business managers represented a factor for the failure of firms in Ghana. Education of Small business 
managers is important for the success of their businesses. Unfortunately, the Cameroonian education system does not help towards business success.

\section{ii. Previous Experience}

In the quantitative phase of the study, previous work experience was considered to have a great impact on the success of Small business managers in Bamenda. Descriptive statistics indicated that Small business managers of both successful and less successful Small businesses tend to have a reasonable number of years of work experience. However, the relevance of the work experience to the business was more highly correlated for the successful firms than their less successful counterparts. Results of the inferential analysis, corroborate the findings of the descriptive analysis and further revealed interesting findings with respect to the previous experience factor. Contrary to expectations, the study did not find significant differences between Small business managers of successful and less successful Small businesses in Bamenda, in relation to the number of years of work experience. However, significant differences were found between the two groups in relation to the relevance of experience to the business. The finding supports the study of [26] who found that poor professional experience was a strong failure factor for Small businesses in Cameroon.

\section{iii. Family Background}

The quantitative phase unveiled important findings about the family background factor. Data analysis indicated that family background tends to influence the success of Small business managers in Bamenda. Descriptive statistics showed that Small business managers of successful firms have relatively more educated parents than Small business managers of less successful firms. This result, shown in the descriptive analysis, seems to corroborate the study of [5] about motivations of Cameroonians to be small business managers. Specifically, [5] found that half of the interviewed Cameroonian small business managers came from families where the father or mother, considered as their role model, was self-employed. In addition, The inferential analysis, using the Mann-Whitney U test, further supports the results of descriptive statistics by illustrating significant differences between the Small business managers of less successful and successful Small businesses in Bamenda, in relation to family background.

\subsubsection{Personality Characteristics}

\section{i. Need for Achievement}

From the quantitative phase, the variable need for achievement was found to have positive impact on the success of Small business managers in Bamenda. Descriptive statistics identified the need of achievement as a common trait for Small business managers of both successful and less successful Small businesses in Bamenda. This result conforms to the findings of [5] who found that high need for achievement was identified as a common trait for Cameroonian small business managers. However, interestingly, significant differences were found between the two groups. Results of the inferential analysis, revealed that the need for achievement was higher for Small business managers of successful firms than for their less successful counterparts.

\section{ii. Locus of Control}

In the quantitative phase of the study, the variable locus of control was found to have no significant association with business success. It was apparent from the descriptive statistics that Small business managers of both successful and less successful firms expressed a neutral opinion in relation to locus of control. In addition, the results obtained from the inferential analysis, using showed no significant differences between the two groups. Respondents believed in working hard to achieve success but that destiny plays a major role in determining such success. A plausible explanation for this result could be related to the religious background of the respondents who were Christains. In Christainity, believers have to believe in destiny, or more accurately, divine destiny. This finding is in agreement with the [5] findings which revealed that the prevailing thought among Cameroonian small business managers was that individuals should make their greatest effort to accomplish something, but that the result is subject to their destiny, which is related to what God has predicted for their lives. Conversely, the result of the present study does not support some other studies in different contexts [13] which found that internal locus of control was positively correlated with small business managerial success.

\section{iii. Propensity for Risk Taking}

Interesting findings were found about the propensity for risk taking. Although descriptive statistics revealed that Small business managers of both successful and less successful firms tend to agree about the importance of taking risks in ensuring the success of their businesses, the inferential analysis, using Mann-Whitney $U$ test unfolded significant differences between the two groups. The finding suggests that the Small business managers of successful Small businesses have higher propensity for risk-taking than their less successful counterparts. This finding shows similarity to several studies in different contexts. However, it is not consistent with the study of [18].

\subsubsection{Competences \& Skills of the Small Business Manager}

\section{i. Managerial Competences}

Quantitative data analysis showed that managerial competences are crucial for the success of Small business managers in Bamenda. Results of the descriptive analysis revealed that managerial competences were regarded as having great importance by Small business managers of both successful and less successful firms. The finding of the study corroborates the finding of [26] which revealed, based on a sample of 56 bankrupt enterprises in Cameroon; that $70 \%$ of failures were due to poor leadership and mismanagement. In addition, the finding is consistent with that of other studies in different contexts and supports the finding of [10] which 
revealed that good management skills are one of the factors most critical to the success of South Pacific islanders' small business managerial activities.

However, although managerial competences were considered to be very important, it was apparent that the magnitude of such importance varied for both groups. Results of the inferential Mann-Whitney U test indicated that the perceived importance of managerial competences for the success of Small business managers was stronger for Small business managers of successful businesses than for their less successful counterparts. It should be noted here that the level of managerial competences could be linked to size of the firm which was discussed above. As argued by [11], as firms grow, small business managers need to develop their leadership and management capabilities in response to the successive internal crises.

\section{ii. Small Business Managerial Competences}

The quantitative phase of the study revealed that small business managerial competences were considered to be important for the success of Small business managers in Bamenda. Descriptive statistics indicated that Small business managers of both successful and less successful businesses viewed small business managerial competences as crucial for the success of their businesses. Specifically, a high importance was placed on the ability to scan the environment and identify customer needs. The results confirm [24] view that the ability to select high quality opportunities and devise appropriate strategies to turn these opportunities into reality may have a considerable impact on venture performance. Furthermore, results of the inferential analysis, using the Mann-Whitney U test, showed no significant differences between Small business managers of both successful and less successful Small businesses in Bamenda, in relation to the importance of small business managerial competences. This suggests that both groups confirmed that small business managerial competences are strong factors of business success.

\section{iii. Functional Competences}

Findings of the quantitative phase of the study suggest that functional competences play an important role in the success of Small business managers in Bamenda. Descriptive statistics indicated that Small business managers of both successful and less successful businesses viewed functional competences as central to the success of their businesses. Specifically, a high importance was placed on the businessrelated competences. This conforms to the argument of [4] who argued that technical or industry-related skills are an important source of "expert" power that legitimizes the small business manager in the eyes of his/her staff, and assists in the implementation of the small business manager's plan. In addition, findings of the quantitative phase are in line with the view of [10] who claims that it is essential for small business managers to acquire venture-specific skills to provide sustainable competitive advantage for their ventures.

The findings of the quantitative phase confirm that functional competences are strong factors of business success for Small business managers of both successful and less successful Small businesses in Bamenda. However, significant differences on the importance of such competences existed between the two groups. Results of the inferential analysis, using the Mann-Whitney U test, revealed that the perceived importance of functional competences to the success of Small business managers was stronger for the Small business managers of the successful businesses than for the less successful ones.

\subsection{Micro Environmental Factors}

\subsubsection{Size of the Enterprise}

The quantitative data analysis revealed a strong correlation between the self-reported size of the firm and business success. Descriptive statistics indicated that the average number of employees and the average annual turnover were far higher for the successful firms than for the less successful ones. Although the findings suggested that the bigger the firm, the more likely it is to be more successful, a conclusion about causality or even directionality cannot be established simply because of the observation of such correlation.

The findings of this quantitative phase, however, corroborates the findings of $[10,20,24]$, who concluded that the larger the firm, the more likely it was to be successful. Conversely, the finding seems to be at odds with [26], at least in terms of growth. In his study, [26] suggested that size has a negative impact on growth of firms in Cameroon. His study found that smaller firms grow very fast. However, it can be argued here that size is perhaps a manifestation of past success, which might have generated growth. Furthermore, as this quantitative phase of the research study asked Small business managers to evaluate the success of their firms, the existence of a larger business might also tend to make these Small business managers rate them as successful.

\subsubsection{Age of the Enterprise}

The findings of the quantitative phase suggested that the self-reported age of the firm has an impact upon the success of Small business managers in Bamenda. Descriptive statistics indicated that the majority of businesses in the sample which have existed for more than five years could be described as successful. Furthermore, results of the inferential analysis, showed significant differences between successful and less successful Small businesses in Bamenda, in relation to the self-reported age of the business. Findings seemed to indicate that the older the business, the more likely it is to be successful. Again, a conclusion about causality or directionality cannot be established here. It can be argued that this finding derived as a result of previous success, in which, perhaps, several causal factors mediated between age and success. For example, it can be suggested that the ageing of a firm tends to increase its network of relationships, and this could engender the appreciation of success.

The study of [26] found a negative correlation between firm age and growth of firms in Cameroon. The relationship between growth and success is complex. In this study, it can be suggested that successful firms learn how to be 
successful as they grow older. Furthermore, the present finding seems to be consistent with the study of [26], who found that the young firms tend to have a high failure rate; age demonstrated a lack of failure. In addition, the result of this study corroborates the findings of a great deal of the previous work in different contexts between age and business success.

\subsubsection{Financial Resources}

The financial resources factor was rated as having the greatest impact on the success of enterprises. In the quantitative phase of the study, descriptive statistics showed that Small business managers of both successful and less successful businesses viewed financial resources as a very important factor that influences the success of their enterprises. The importance of finance was further reinforced by participants in the qualitative phase. This finding is in line with other previous studies in the USA. [16] undertook an exploratory study about feminine entrepreneurship in Cameroon. Specifically, using a survey questionnaire on a sample of 579 women Small business managers, her study reported that the second most frequent problem faced by small business managers and which was common for both women and men was lack of finance. In another study conducted by [26], findings revealed that insufficient financial resources were among the failure factors of Small businesses.

Results of this quantitative phase of the study also accord with a large number of other previous studies in different contexts. In a quantitative study about the factors related to the competitive ability of firms in Cameroon, [20] identified finance, an aspect of management of the financial resources, as a very important factor for business competitiveness. In addition, [19] for example, argued that in a competitive business environment, access to finance is an important component that facilitates entry, exit and growth of firms and therefore is essential for the development process.

The constraints related to financial resources and their impact on the success of businesses, have been covered extensively in the literature. In the quantitative phase of the research study, results of inferential analysis using the MannWhitney U test showed no significant differences between Small business managers of both less successful and successful Small businesses, in relation to the constraints related to financial resources. This implied that both groups were in total agreement that financial constraints are very challenging and can consequently inhibit their success. The perceived high cost of credit was considered by respondents to be a key obstacle to the success of the business. In addition, the findings support [19] who showed that Small business managers of Small businesses perceive access to finance and cost of credit to be greater obstacles than do those of large firms and that these factors affect their growth.

Semi-structured interviews did provide important insights about the constraints related to finance. Findings revealed that obtaining credit from financial institutions can be achieved provided that the enterprise presents a strong dossier (business plan) that includes all of the information required to request a loan. However, banks are very selective in granting credit. This could be explained by the high demand for credit in Cameroon that far exceeds supply. Interviewees indicated that banks usually demand asset collaterals which are normally very high.

In tackling the constraints related to financial resources, findings revealed that some Small business managers of Small businesses use trade credit and microloans from microfinance institutions as an external financing source to enhance their performance. The use of trade credit by Small business managers of Small businesses in Bamenda is in line with the academic literature that considers trade credit as an external source of finance for small and medium companies in countries with less developed financial markets.

\subsection{Macro-environmental Factors}

\subsubsection{Customer Relationships}

In the quantitative phase of the study, the Small business managers of both less successful and successful Small businesses identified customer relationships as very important to business success. Descriptive statistics indicated that the Small business managers of both successful and less successful firms considered customer relationships vital for ensuring success. Moreover, results of inferential analysis using the Mann-Whitney $U$ test showed no significant differences between the two groups on their perceptions about the importance of customer relationships. Findings of the quantitative phase support results of different studies on critical success factors of Small businesses in many contexts. The findings were further validated by the qualitative phase where the interviewees did stress the importance of developing strong relationships with customers in its impact on the success of Small businesses. This is consistent with the findings of a study by [21]. Specifically, their study that undertook a survey questionnaire among 203 Small businesses in 3 cities in the Republic of Botswana revealed that the quality customer relationships was rated high in its impact on the performance of firms.

Interviewees in the qualitative phase of the study further highlighted the importance of customer relationship in achieving competitive advantage in the market. This is in line with the findings of a quantitative study by [20], where direct contact was made with chief executive officers (or managers) or members of the management team of 96 enterprises in Cameroon. The study revealed that among the five important factors related to the competitive ability of the firm was marketing strategy, where customer loyalty and customer retention were important.

Given the importance of maintaining strong relationships with customers, reference to certain strategies were revealed in the qualitative phase. For those in business-to-business markets, the link between equipment and commitments was developed through investment in lean production and pricing strategies. The elimination of non-value added elements in the production process could enable firms to charge low prices to customers and therefore ensure their retention. 


\subsubsection{Supplier Relationships}

Survey responses in the quantitative phase of the study indicated that Small business managers of both successful and less successful Small businesses considered suppliers very important to the perceived success of their businesses. Descriptive statistics showed that both groups considered suppliers important to business success. However, results of inferential analysis using the Mann-Whitney test found differences between Small business managers of less successful and successful Small businesses in relation to their perceptions of such importance. Surprisingly, results suggested that Small business managers of less successful businesses considered suppliers more important for business performance than their successful counterparts.

Semi-structured interviews confirmed the findings of the quantitative phase. Participants emphasized the importance of developing relationships with suppliers to the success of their businesses. This corresponds to the findings of [1]. Based on a survey of Australian boat-builders, [1] contended that small-firm success was associated with greater investment in the supplier relationship.

Findings of the qualitative phase further revealed that relationships between the buyer and the supplier can result in opportunism and conflict. Hence, governing such relationships is a crucial task for business Small business managers to ameliorate the exchange process. Business Small business managers referred to the word "partenariat" as the formal mechanism used to govern such relationships.

\subsubsection{Competition}

Having a competitive advantage over competitors was considered by Small business managers as an important factor contributing to the success of Small business managers in Bamenda. In the quantitative phase of the study, descriptive statistics and results from the Mann-Whitney U test showed that Small business managers of both successful and less successful businesses considered competitive advantage as an important factor in ensuring the success of their businesses. The importance of competitive advantage was further stressed by participants during the in-depth semi-structured interviews undertaken in the qualitative phase of the study.

The constraints related to competition and its impact on the success of businesses, have been covered extensively in the literature. In the quantitative phase of this study, results of inferential analysis using the Mann-Whitney $U$ test showed no significant differences between Small business managers of both less successful and successful Small businesses, in relation to the constraints of competition. This suggests that both groups consented that constraints related to competition are very challenging and consequently have an inhibiting effect on their success.

Surprisingly, an important finding, in relation to the competition constraints, was that the wide spread of smuggling activities constitute a hurdle, especially for agrifood firms, in achieving competitive advantage. Participants in the qualitative phase argued that products or goods smuggled from Nigeria, create an environment of unequal competition that hampers the thriving and success of their businesses. They further highlighted that the smuggled products are transported to the different markets spread all over the country.

During discussions with participants, a number of strategies were raised whose purpose was to gain a competitive advantage over their rivals. Findings of the qualitative phase suggested that the concepts of lean production are used in order to stay competitive by offering lower prices than competitors. Furthermore, findings clearly indicated that in a very competitive environment, product diversification is a very efficient strategy that has positive influence on the performance of firms. Engaging in the process of product diversification could help businesses to attain a competitive advantage in the market.

\subsection{Socio-cultural Factors}

\subsubsection{Networking}

Networking was widely considered by participants to have a pivotal impact on the success of Small business managers in Bamenda. In the quantitative phase of the study, descriptive statistics showed that Small business managers of both successful and less successful businesses viewed networking a very important factor that influences the success of their enterprises. Furthermore, results of inferential analysis using the Mann-Whitney $U$ test found significant differences between the two groups in relation to the networking factor. While Small business managers of successful businesses tended to have a wide access to networking, those from less successful businesses were characterised as having limited access to networking.

The importance to networking was further reinforced by participants in the qualitative phase of the study. Furthermore, findings revealed that business networking has a great impact on financial performance. Participants in the qualitative phase further highlighted the importance of networking as one of the strongest business tools to get the latest information related to the business environment. Information could be very helpful in scanning new opportunities in the market. This finding suggests a close relationship with the information factor that was discussed above. It can be suggested that the ability to develop relationships and to build a method of business that strengthens and manages relationships is a significant factor in Cameroonian business and society in general.

\subsubsection{The Entrepreneurial Team}

The effect of the workforce on success of Small business managers did not emerge from the initial literature review but did so during the qualitative phase. The qualitative data analysis showed that the workforce is a key factor for the success of Small business managers in Bamenda. The role of the workforce in influencing success is a factor that has been noted by several authors. For example, in his review of the determinants of firm growth in Cameroon, [26] found that among the main factors that hinder business performance, in particular growth, is lack of access to skilled workers and 
managers. In his study of the success of Small business managers, [5] found that unreliable employees were considered to be among the problems that inhibit the success of Small business managers in Turkey.

The in-depth discussions with participants in the qualitative phase unfolded a very interesting finding about the workforce in Bamenda. According to business Small business managers, the major problem is not shortage of manpower but the lack of motivated workers in Bamenda. Over half of the participants in the qualitative phase reported that Bamenda workers, in particular males, are indolent and unmotivated. It is difficult to explain this result, but it might be related to the specific characteristics of the male workforce in Bamenda. This finding is somewhat consistent with the study of [5]. However, the study has been unable to demonstrate that the lack of access to skilled labour hinders business performance, and particularly growth, as argued by [26]. This could be explained by the high rate of unemployment in Cameroon. While it would appear that with a high rate of unemployment, there should be an available pool of skilled labour, this is significantly reduced by migration to other regions of Cameroon on the part of qualified workers. This may be a particularly acute issue in the Bamenda region because of the political instabilities in bamenda and chronic lack of infrastructure.

In contrast to their views on the male workforce, Small business managers of textile firms, as well as car spare parts Agribusiness firms, disclosed that female employees tend to show high levels of commitment and hard work. There are several possible explanations for this result. It may be that local women work really well with dexterous tasks, or their position in society encourages them to develop dependability.

\section{Conclusion}

As for the external factors, it is widely recognized that successful organizations are those that best adapt to fit the opportunities and the constraints inherent in the environment in which they operate, the external environment of the enterprise can be classified into two dimensions, namely the general and competitive environments. The general environment consists of the political-legal, macroeconomic, socio-cultural, technological, demographic and global factors that might affect the organization's activities. On the other hand, the competitive environment consists of other specific organizations that are likely to influence the profitability of the enterprise, such as customers, suppliers and competitors. Several previous studies in both developed and developing countries have identified a range of external performance factors that relate to the general as well as the competitive environment of the firm

This study has shown that understanding the success of small businesses from the perspective of small business managers is a complex challenge. Findings of the two phases of the study showed that a host of internal as well as external factors, which are usually moderated by other variables, seem to influence business success in Bamenda. However, while many factors are conceptually similar to other studies in different contexts, others are context-based and closely linked to the specific characteristics of the situation in Bamenda. This study confirms that general finding of diversity and specificity but offers a conceptual model that summarizes the key factors identified by Small business managers in this research. According to business Small business managers, the major problem is not shortage of manpower but the lack of motivated workers in Bamenda. Over half of the participants in the qualitative phase reported that Bamenda workers, in particular males, are indolent and unmotivated. It is difficult to explain this result, but it might be related to the specific characteristics of the male workforce in Bamenda. While it would appear that with a high rate of unemployment, there should be an available pool of skilled labour, this is significantly reduced by migration to other regions of Cameroon on the part of qualified workers. This may be a particularly acute issue in the Bamenda region because of the political instabilities in bamenda and chronic lack of infrastructure. This finding suggests a close relationship with networking and business success. It can be suggested that the ability to develop relationships and to build a method of business that strengthens and manages relationships is a significant factor in Cameroonian business and society in general.

\section{References}

[1] Aidis, R., \& Mickiewicz, T. (2016). Small business managers, expectations and business expansion: lessons from Lithuania. Europe-Asia Studies, 58 (6), 855-880.

[2] Aldrich, H. E., \& Reese, P. R. (2003). Does networking pay off? A panel study of small business managers in the research triangle. In N. Churchill, S. Birley, \& J. Doutriaux.

[3] Babbie, E. R. (2016). The practice of social research (12 ed.). Belmont: Wadsworth, Cengage Learning.

[4] Baum, J., \& Locke, E. A. (2015). The relationship of small business managerial traits, skill, and motivation to subsequent venture growth. Journal of Applied Psychology, 89 (4), 587598.

[5] Benzing, C., Chu, H. M., \& Kara, O. (2016). Small business managers in Turkey: A factor analysis of motivations, success factors, and problems. Journal of small business management, 47 (1), 58-91.

[6] Bolton Committee Report. (1971). Report of the Commission of Inquiry on Small Firms. London: HMSO.

[7] Child, J. (2003). Predicting and understanding organization structure. Administrative Science Quarterly, 18 (2), 168-185.

[8] Emory, C. W., \& Cooper, D. R. (2011). Business research methods (4 ed.). New York: Irwin.

[9] Man, T. W., \& Lau, T. (2014). The context of Business Innovation in Hong Kong: an investigation through the patterns of small business managerial competencies in contrasting Agribusiness environments. Journal of Small Business and Enterprise Development, 12 (4), 464-481. 
[10] Mazzaro, T., Volery, T., Doss, N., \& Thein, V. (1999). Factors influencing Small businesse start-ups. International Journal of Small business managerial Behaviour and Research, $5(2), 48-130$

[11] Nieman, G. (2016). Small business management: A South African approach. Van Schaik Publishers.

[12] OECD, African Development Bank. (2009). African economic outlook 2009. Paris: African Development Bank.

[13] Perez, E. H., \& Canino, R. M. (2009). The importance of the small business manager's perception of "success". Review of International Comparative Management, 10 (5), 990-1010.

[14] Pérez, S., Llopis, A., \& Llopis, J. (2004). The determinants of survival of Spanish Agribusiness firms. Review of Industrial Organisation, 25 (3), 251-273.

[15] Polit, D. F., \& Hungler, B. P. (1999). Nursing research: Principles and methods (6th ed.). Philadelphia: Lippincott.

[16] Sandberg, K. W. (2003). An exploratory study of women in micro enterprises: Gender-related differences. Journal of Small Business and Enterprise Development, 10 (4), 408-417.

[17] Sapienza, H., \& Grimm, C. (2007). Founder characteristics, start-up process and strategy/structure variables as predictors of shortline railroad performance. Owner-managership Theory and Practice, 22 (1), 5-24.

[18] Siegel, R., Siegel, E., \& MacMillan, I. C. (2003). Characteristics distinguishing high-growth ventures. Journal of Business Venturing, 8 (2), 169-180.

[19] St Jean, E., Julien, P. -A., \& Audet, J. (2014). Factors associated with growth change in 'gazelles'. Journal of Enterprising Culture, 16 (2), 161-188.
[20] Takwi Mbah (2014). Contemporary business management, Green Edition. McDavid consulting group

[21] Temtime, Z. T., \& Pansiri, J. (2004). Small business critical success/failure factors in developing economies: some evidences from Botswana. American Journal of Applied Sciences, 1 (1), 18-25.

[22] The Organisation for Economic Co-operation and Development. (2014). OECD Small business and Ownermanagership outlook. Paris: OECD Publishing.

[23] The World Bank. (2009). Doing Business 2009. Washington, DC: The World Bank.

[24] The World Economic Forum, The International Bank for Reconstruction and Development/The World Bank, and The African Development Bank. (2009). The Africa competitiveness report 2009. Geneva: World Economic Forum.

[25] Wang, C. K., \& Ang, B. L. (2004). Determinants of venture performance in Singapore. Journal of Small Business Management, 42 (2), 347-363.

[26] Weinzimmer, L. G. (2003). A replication and extension of organizational growth determinants. Journal of Business Research, 48 (1), 35-41.

[27] Woldie, A., Leighton, P., \& Adesua, A. (2016). Factors influencing Micro Enterprises (Small businesses): an exploratory study of owner/manager and firm characteristics. Banks and Bank Systems, 3 (3), 5-13.

[28] Zikmund, W. G., Babin, B. J., Carr, J. C., \& Griffin, M. (2016). Business research methods (8th ed.). South-Western, Cengage Learning. 